\title{
Influence of Multi-directional Dynamic Stabilization Exercise on Thickness of Abdominal Muscles
}

\author{
Jae-Young Yu', Jea-Cheol Park², Jin-Gyu Jeong ${ }^{2}$ \\ 'Department of Physical Therapy, Graduate School of Dongshin University, Naju; '2Department of Physical Therapy, Chunnam Techno University, \\ Gokseong-gun, Jeollanam-do, Korea
}

Purpose: The purpose of this study was to examine the influence of multi-directional dynamic stabilization exercise on the thickness of the external oblique abdominis, internal oblique abdominis, and transversus abdominis.

Methods: For the study subjects, 40 adults were taken and divided into two groups and stabilization exercise was performed for 6 weeks. Changes in muscle thickness during the pre-experimental period, and at 2 weeks, 4 weeks, and 6 weeks were analyzed using repeated ANOVA.

Results: The thickness of the external oblique abdominis, internal oblique abdominis, and transversus abdominis in the multi-directional dynamic stabilization exercise group showed significant differences per period and an interaction was observed between period and group $(p<0.01)$, while there were no significant differences in changes per group $(p>0.05)$.

Conclusion: The effects of multi-directional stabilization exercises on abdominal muscle thickness differed. The results presented herein can be utilized as basic data for future studies and in development of rehabilitation treatments.

Keywords: Thickness, Ultrasonograph, Computerized dynamic posturography, Multi directional dynamic stabilization exercise

서 론

인간의 활동 시 힘을 생성해내는 신체의 중요부위는 몸통부이며,' 이 부위의 안정성 향상은 다양한 활동을 가능하게 한다. ${ }^{2}$ 안정성에 관련 된 몸통을 구성하는 근육은 크게 표재성 근육인 배곧은근, 배바깥 빗근과 심부성 근육인 배속빗근, 배가로근, 뭇갈래근으로 구분되며 이러한 근육들은 부하로부터 척추를 보호하고 표재성 근육의 작용 으로 움직임이 발생할 때 심부성 근육들이 그 움직임을 안정적으로 이루어지게 한다. 심부성 근육인 배속빗근과 배가로근은 움직임에 대한 허리 안정성을 제공하는 반면 뭇갈래근은 작은 움직임을 조절 하는 데 작용한다. 척추의 안정성을 얻기 위해서는 표재성 근육과, 심부성 근육의 근력과 지구력이 필요하며 근육의 동시수축이 중요 하다. 이러한 요소가 적절하게 작동되지 않으면 허리의 불안정성을 일으키며, 허리 통증을 발생시키는 중요한 원인 중 하나이다. ${ }^{6}$ 이러한 몸통 근육의 동시수축과 척추의 안정성을 회복시킬 수 있는 일반적 인 몸통 안정화 운동으로 많은 선행연구가 보고되고 있다. ${ }^{710}$ 하지만 기존 몸통 안정화 운동들은 따라 하기 어려운 운동방법과 부정확한

Received Jul 11, 2016 Revised Jul 28, 2016

Accepted Aug 29, 2016

Corresponding author Jin-Gyu Jeong

E-mail ptj8763@hanmail.net
운동강도, 또한 한 방향 운동 면의 기능만 개선시키고 개별 근육의 강화 훈련에서는 정도가 부족한 실정이다.

이러한 점을 보완하여 최근 개발된 다 방향 동적 안정화 운동은 컴 퓨터 동적 균형 조절장치(computerized dynamic posturography)라고 도 불리며, 심부 근육의 강화에 특별한 기능적 수행으로 구성되어 신 체적 기능의 향상에 영향을 준다고 하였다.1" 다 방향 동적 안정화 운 동은 정적 또는 동적 상태에서 또는 기립 자세에서 정략적 자세조절 에 사용되는 기술로 ${ }^{12-13}$ 외부 환경을 가상으로 제공하여 기울임을 저 항으로 이용하여, 몸통근의 수축을 유도할 수 있는 장치로, 정상성인 의 신체교육과 스포츠훈련 비정상적인 상태의 성인에서는 균형 장애 진단이나 물리치료 자세재교육을 통해 자세조절에 영향을 기술이라 고 하였다. ${ }^{14}$

$\mathrm{Kim}^{15}$ 은 기울임 동작 시 몸통 근과 다리 근육의 활성도 변화 연구 에서 기울임 동작으로 몸통과 다리 근육의 협응 수축을 유발하기 위 한 알맞은 운동방법이라고 하였고, $\mathrm{Kim}$ 과 $\mathrm{Kim}^{16}$ 은 퇴행성 디스크 환 자의 통증과 허리 안정화 근육의 근력 변화 연구에서 유의한 차이가 있었다고 보고하였다. 또한 만성요통환자를 대상으로 3차원 안정화
Copylight (C) 2016 The Korea Society of Physical Therapy

This is an Open Access article distribute under the terms of the Creative Commons Attribution Non-commercial License (Http:// creativecommons.org/license/by-nc/4.O.) which permits unrestricted non-commercial use, distribution, and reproduction in any medium, provided the original work is properly cited. 
운동을 이용한 4 주간 운동치료를 통해 허리근력 증가와 통증을 감 소시키는 효과를 확인했으며 ${ }^{17}$ 또 다른 연구에서는 3 차원 기울임 운 동을 4 주간 시행 후 균형 변화 연구에서 균형 향상에 도움을 준다고 보고하였다. ${ }^{18}$

이와 같이 다 방향 동적 안정화 운동을 이용하여 근활성도와 근 력, 균형의 긍정적인 효과는 보고되고 있지만 신체의 기저면에서 운 동의 면과 축을 변화시켜 신체의 모든 3 면의 동작과 전체적인 근육의 연속적인 수축(구심성, 원심성 및 등척성 수축)을 유발하여 초음파 를 이용한 몸통근의 구조적 변화를 밝힌 연구는 전무한 실정이다.

그러므로 몸통 근육 중 안정화에 관여하는 배바깥빗근과 배속빗 근, 배가로근의 근두께 변화를 다 방향 동적 안정화 운동과 교각운동 을 비교하여 근육의 구조적 변화에 대한 기초자료를 제시하고자한다.

\section{연구 방법}

\section{1. 연구대상}

본 연구는 20 대 건강한 성인 40 명을 대상으로 근 골격계 질환과 내. 외과적 질환이 없는 자로 선정하여 다 방향 동적 안정화 운동군 20 명, 교각운동군 20 명을 무작위로 배정하여 실험 전 연구 목적과 방법 을 설명하여 자발적으로 연구 참여를 동의한 자와 실험동의서를 작 성하여 연구를 진행하였다. 실험대상자의 분류는 연구자의 임의배정 방식에 의하여 무작위로 설정되었으며 실험 전 동질성 검정 결과 연 령, 신장, 체중, 체질량지수에서 유의한 차이가 없어 동일한 집단임을 확인하였다(Table 1).

\section{2. 실험방법}

다 방향 동적 안정화 운동은 자세균형 측정시스템(Space Balance 3D, Cyber Medic, Co., Korea)을 이용하여 무릎관절 $180^{\circ}$ 폄, 어깨관절 $30^{\circ}$ 굽힘 자세를 취한 후 손은 양 팔꿉 관절을 잡은 상태를 유지한 상태 에서 측정시스템에 저장된 물고기 피하기 게임을 난이도 1단계 모드 로 훈련하였다.

교각운동(bridge exercise)는 안정면 매트 위에 등을 대고 무릎은 $60^{\circ}$ 로 구부리고 양쪽 손바닥과 발바닥은 매트의 바닥에 붙여서 반드 시 눕힌 후 운동을 하였고 무릎과 어깨가 일직선이 되도록 엉덩 관절

Table 1. General characteristic of subjects

\begin{tabular}{lccc}
\hline & Group 1 $(n=20)$ & Group 2 $(n=20)$ & $p$ \\
\hline Year (age) & $24.4 \pm 3.04$ & $25.0 \pm 2.56$ & 0.086 \\
weight $(\mathrm{kg})$ & $65.3 \pm 2.87$ & $63.9 \pm 9.20$ & 0.818 \\
muscle mass & $26.7 \pm 5.43$ & $27.9 \pm 5.94$ & 0.399 \\
BMI $\left(\mathrm{kg} / \mathrm{m}^{2}\right)$ & $22.7 \pm 2.94$ & $21.9 \pm 2.47$ & 0.465 \\
\hline
\end{tabular}

Group 1: multi directional dynamic stabilization exercise. Group 2: bridge exercise.
을 천장을 향해 높게 들어 유지하며 1 회 운동 시간은 20 초로 유지하 였다. 그룹별 운동프로그램은 일일 준비운동 5 분, 본 운동 20 분, 마무 리운동 5 분, 총 30 분주 2 회, 총 6 주간 실시하였다.

\section{1) 측정도구}

복부 근육의 두께 측정을 위해 초음파영상장치를(Mylabone, Esaote, Italy) 이용하여 측정하였다. 주파수 변조 범위는 $10 \mathrm{MHz}$ 로 하였고 초 음파 변환기는 $7.5 \mathrm{MHz}$ 의 선형탐촉자(Linear transducer, SL3323)를 사 용하였으며 민감도는 $\mathrm{G} 50$ 과 동적범위C4로 고정하여 사용하였다. 검 사자 간의 차이를 최소화하기 위해 복부의 해부학적 지식과 초음파 검사기에 숙달된 물리치료사 1 인의 측정자로 측정하였으며, 측정 시 기별 측정부위를 정확히 유지하기 위해 수술용 펜으로 표시 후 시행 하였다. 근두께 측정은 대상자가 바로 누운 자세에서 무릎관절 아래 베개를 받치고 복부 우측 부위만 측정하였다. 또한 $\operatorname{TrA}$ 의 두께 변화 양상에서 호흡 주기가 영향을 미칠 수 있다는 Hodges과 Gandevia ${ }^{19}$ 의 연구결과에 따라 호기 마지막 단계에서 측정하였고, 변환기를 엉 덩뼈 능선의 상단부에 $\operatorname{TrA}$ 를 위치시키고 복부의 중앙으로 이동하면 서 $\mathrm{EO}, \mathrm{IO}, \operatorname{Tr} A$ 가 모두 뚜렷하게 보일 때 측정하였다. $\mathrm{EO}, \mathrm{IO}, \operatorname{Tr} A$ 의 두 께 측정은 $\mathrm{IO}$ 의 근막과 $\mathrm{TrA}$ 의 근막이 만나는 지점으로부터 $13 \mathrm{~mm}$ 떨어진 지점을 측정하였고, ${ }^{20} 3$ 회 반복 측정한 후 평균값을 근육의 두 께로 정하였다.

\section{2) 분석 방법}

수집된 자료는 SPSS 18.0 통계프로그램을 이용하여 평균과 표준편차 를 산출했으며, 두 그룹의 훈련 전, 2 주 후, 4 주 후, 6 주 후의 측정 변인 에 대한 변화를 알아보고자 반복측정 분산분석(repeated ANOVA)을 이용하였다. 개체 내 효과 검정에서 시기와 군 간 상호작용이 있는 경 우에는 일원배치분산분석(one way ANOVA)을 이용하였고 사후검정 으로는 Scheffe의 다중비교분석을 하였다. 통계학적 유의성을 검정하 기 위해 유의수준은 0.05 로 하였다.

\section{결 과}

\section{1. 배바깥빗근의 근두께 변화}

각 군의 배바깥빗근의 근두께에 대한 반복측정 분산분석 결과 근두 께 변화에서 시기별, 시기와 군 간 상호작용은 유의한 차이를 보였고 $(\mathrm{p}<0.01)$, 집단 간 변화에서 유의한 차이가 없었다 $(\mathrm{p}>0.05)$ (Table 2) (Figure 1).

\section{2. 배속빗근의 근두께 변화}

각 군의 배속빗근의 근두께에 대한 반복측정 분산분석 결과 근두께 
Table 2. Comparison of trunk muscle thickness

\begin{tabular}{|c|c|c|c|c|c|c|c|c|c|}
\hline & & \multirow{2}{*}{$\begin{array}{c}\text { Pre } \\
\text { a }\end{array}$} & \multirow{2}{*}{$\begin{array}{c}2 \text { weeks } \\
\text { b }\end{array}$} & \multirow{2}{*}{$\begin{array}{c}4 \text { weeks } \\
\text { c }\end{array}$} & \multirow{2}{*}{$\begin{array}{c}6 \text { weeks } \\
\mathrm{d}\end{array}$} & \multicolumn{4}{|c|}{$\mathrm{F}$} \\
\hline & & & & & & Time & Group & TimeX Group & Post-hoc \\
\hline \multirow[t]{2}{*}{ EOT } & Group1 & $5.45 \pm 1.10$ & $5.90 \pm 0.99$ & $6.53 \pm 0.95$ & $7.12 \pm 0.91$ & \multirow{2}{*}{$74.406^{*}$} & \multirow{2}{*}{0.107} & \multirow{2}{*}{$18.785^{\star}$} & \multirow{2}{*}{$\begin{array}{l}a<c, d \\
b<d\end{array}$} \\
\hline & Group2 & $5.93 \pm 1.17$ & $5.99 \pm 1.18$ & $6.21 \pm 1.16$ & $6.44 \pm 1.15$ & & & & \\
\hline \multirow[t]{2}{*}{ IOT } & Group1 & $6.61 \pm 0.80$ & $6.99 \pm 0.68$ & $7.42 \pm 0.68$ & $8.04 \pm 0.62$ & \multirow{2}{*}{$84.372^{\star}$} & \multirow{2}{*}{2.449} & \multirow{2}{*}{$6.621^{*}$} & \multirow{2}{*}{$\begin{array}{c}a<c, d \\
b<d\end{array}$} \\
\hline & Group2 & $6.40 \pm 1.38$ & $6.54 \pm 1.39$ & $6.87 \pm 1.33$ & $7.15 \pm 1.36$ & & & & \\
\hline \multirow[t]{2}{*}{ TrAT } & Group1 & $3.20 \pm 0.53$ & $3.40 \pm 0.42$ & $3.86 \pm 0.57$ & $4.34 \pm 0.59$ & & & & $a<c, d$ \\
\hline & Group2 & $3.70 \pm 0.67$ & $3.73 \pm 0.67$ & $3.82 \pm 0.81$ & $4.43 \pm 0.87$ & $32.961^{*}$ & 1.425 & $4.447^{\star}$ & $\begin{array}{l}b<d \\
a<d\end{array}$ \\
\hline
\end{tabular}

EOT: external oblique abdominis thickness, IOT: internal oblique abdominis thickness, TrAT: transverses abdominis thickness, Group1: multi directional dynamic stabilization exercise, Group 2: bridge exercise, Post-hoc: one way ANOVA. ${ }^{*} p<0.05$.

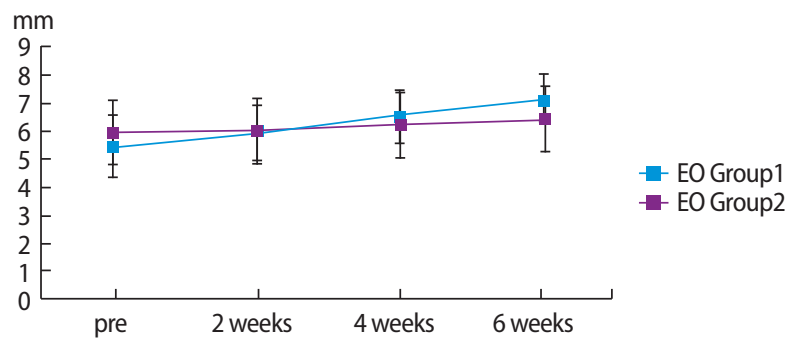

Figure 1. Comparison of external oblique abdominis muscle thickness. EO: external oblique abdominis

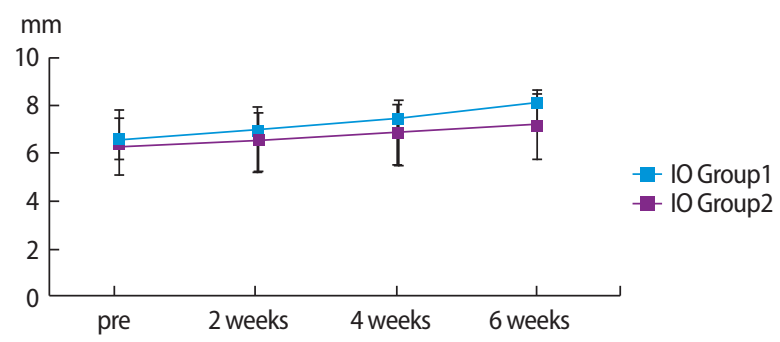

Figure 2. Comparison of internal oblique abdominis muscle thickness. IO: internal oblique abdominis.

변화에서 시기별, 시기와 군 간 상호작용은 유의한 차이를 보였고 $(\mathrm{p}<0.01)$, 집단 간 변화에서 유의한 차이가 없었다 $(\mathrm{p}>0.05)$ (Table 2)

(Figure 2).

\section{3. 배가로근의 근두께 변화}

각 군의 배가로근의 근두께에 대한 반복측정 분산분석 결과 근두께 변화에서 시기별, 시기와 군 간 상호작용은 유의한 차이를 보였고 $(\mathrm{p}<0.01)$, 집단 간 변화에서 유의한 차이가 없었다 $(\mathrm{p}>0.05)$ (Table 2) (Figure 3).

\section{고 찰}

다 방향 동적 안정화 운동은 3 개 면의 기울기를 이용하여 다양한 각 도의 운동과 정확한 운동강도 시간을 설정할 수 있다는 장점과 운동

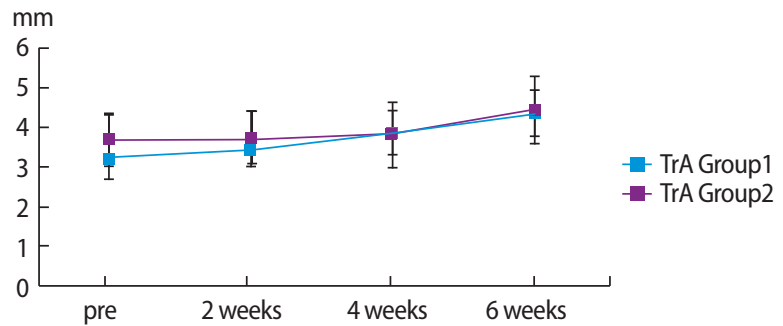

Figure 3. Comparison of transverse abdominis muscle thickness. TrA: transverse abdominis.

강도를 조절할 수 있어 부상에 있어 안전하며 관절의 움직임이 없이 운동할 수 있어 초기 몸통 안정화 운동을 시행하는 사람에게 적합한 운동 장치이다. 또한 기울임을 통해 주동근과 협력근 안정화 근육들 의 수축을 유발하여 근육 간의 협응 수축 체계의 조절을 돕고 기능 적인 자세를 유지할 수 있게 하는 운동 방법으로 전, 후, 좌, 우면 기울 임 동작을 끌어낼 뿐만 아니라 다양한 각도의 조절이 가능하므로 인 체의 기능적 협응 수축의 양상을 기울임 각도에 따라 인체의 협응 수 축력과 역량을 평가 ${ }^{14}$ 및 훈련할 수 있다. 서있는 동안에 지지면을 좁 히는 운동은 근력을 향상하는 가능성이 높다고 하였는데, ${ }^{21}$ 본 운동 은 좁은 지면에서 외부 동요를 받아 골반의 전, 후, 좌, 우 경사를 바로 잡기 위해 몸통근의 수축을 유발하여 근력과 근두께 증가가 발생할 가능성에 가설을 세우고 본 연구를 설계하였고, 이에 본 연구는 다 방향 동적 안정화 운동으로 초음파를 이용하여 시기별로 훈련 전, 2 주 후, 4주 후, 6 주 후로 시기를 나누어 배바깥빗근, 배속빗근, 배가로 근의 근두께를 비교 분석하였다. 본 연구에서 이용된 초음파는 실시 간으로 적용할 수 있고 심부 구조의 측정에 꼭 필요한 장비이며, ${ }^{22}$ 정 적·동적 상태의 운동을 비침습적으로 측정할 수 있으며, 초음파영상 도 신뢰도 연구에서 신뢰도가 높다고 하였다. ${ }^{23}$

$\mathrm{Kim}^{15}$ 은 체 평형 장치를 이용해 각 기울임 각도 차이에 따른 근활 성도 변화 연구에서 후방 기울임과 측방 기울임 시 배바깥빗근의 근 활성도가 유의하게 차이가 있었고, 기울림 각도가 클수록 큰 근활성 도를 보였다고 보고하였고, 만성 요통 환자들을 대상으로 3-D Spatial 
Rotation Device를 이용하여 8주간 훈련 결과 통증과 배바깥빗근과 배속빗근의 근력이 운동 전 $59.05 \%$ 에서 운동 후 $71.6 \%$ 로 $12.62 \%$ 만큼 근력이 향상하여 유의한 차이를 보고하였다. ${ }^{16}$ 많은 연구에서 근두께 변화와 근활성도의 변화의 상관관계를 연구하고 있으며 McMeeken 등 24 은 근두께 변화와 근활성도의 변화는 높은 상관관계가 있다고 보고하여 근육의 근활성도 지표를 근두께 변화의 지표로 볼 수 있다. 본 연구의 근두께 변화에서 배바깥빗근, 배속빗근, 배가로근의 시기 별, 시기와 군 간 상호작용에서 유의한 차이가 발생하여 $(\mathrm{p}<0.01)$, 선 행연구와 비슷한 결과를 나타내었다. 본 연구 결과를 비추어보면 기 울기가 발생하면 배바깥빗근은 다른 복부 근육들과 함께 등척성 지 지를 제공하며 몸통을 조절하여 허리의 운동을 제한한다는 ${ }^{25}$ 연구처 럼 배바깥빗근이 뒤쪽 기울임에 대한 후방 경사되는 골반을 안정화 시키기 위해 근활성도가 증가하였고, 척추의 움직임을 제한하는 데 있어 근섬유가 비스듬한 배바깥빗근과 배속빗근이 역학적으로 더 유용하기 때문에, ${ }^{26}$ 다른 근육들보다 높은 근활성도로 인해 근두께 변화가 발생하였다. 초음파 영상장치를 이용한 연구에서는 남성 21 명 을 대상으로 몸통 회전 시 배바깥빗근, 배속빗근, 배가로근의 두께 변 화 연구에서 몸통 회전 시 배속빗근과 배가로근의 두께변화에 영향 을 준다고 보고하여 몸통 기울임 증가로 인해 두께 변화에서 유의한 차이가 발생한 본 연구 결과와 일치하였다. ${ }^{7}$

군간 차이에서 유의하지 않았던 것은 본 연구에서 주 2 회의 적은 운동량과 총 6주간 적은 훈련기간에서 그 원인을 찾을 수가 있으며 Anders ${ }^{28}$ 는 31 명 대학생 대상으로 운동 강도에 따른 근활성도를 연구 에서 운동강도의 $30-45 \%$ 정도에서 배바깥빗근과 배속빗근과 같은 몸통 안정화 근육의 최대 근활성도의 $50 \%$ 값이 측정되었다고 보고 하였는데, 본 연구에서는 처음부터 운동 마지막 단계까지 1단계 모드 로 훈련을 하여 운동강도가 약하여 이러한 결과가 발생한 것으로 생 각된다. 하지만 교각 운동군은 훈련 전과 6 주 후에 배가로근만 근두 께 증가가 발생한 반면 다 방향 기울임 체 평형운동은 4 주 만에 모든 근육이 유의한차이가 발생한 것은 임상적으로 큰 의미가 있다.

본 연구에서 심부성 근육보다 표재성 근육의 두께가 좀 더 증가하 였다. 올바른 운동 조절을 위해서는 적절한 감각 바이오 피드백이 주 어져야 하며, ${ }^{29}$ 시각 바이오 피드백 운동 조절을 변화시켜 선택적 근 활성도 강화에 도움을 준다. ${ }^{30}$ Sung과 Leininger ${ }^{31}$ 는 요통환자 대상으 로 눈 뜬 상태와 감은 상태로 척추부위 동작 분석 결과 허리에 가중 된 부하와 기립 자세에서의 불안정성은 신체의 결함을 피하려고 통 증이 유발되며 눈을 뜬 상태보다 감은 상태에서 안정성이 현저히 감 소하였다고 보고하여, 감각 바이오 피드백의 역할을 강조하였다. 본 연구에서는 물고기 잡기 게임 모드로 시각적 피드백을 제공하였고 신체 정렬을 맞추기 위해 배바깥빗근과 배속빗근, 배가로근의 근활 성도가 증가한 것이며, 시각적 바이오 피드백을 제공할 때는 배바깥
빗근의 활성도가 증가되고, 제공하지 않았을 때는 배속빗근의 활성 도가 증가된다는 ${ }^{32}$ 연구 결과처럼 본 연구에서도 배바깥빗근의 근두 께가 보다 증가되었다.

본 연구의 적은 대상자와 건강한 성인 대상으로 한정하여 일반화 하는 데 어려움이 있고 여러 강도, 기울임을 사용하지 않고 1단계 모 드만 사용했다는 점이 제한점으로 남는다. 차후에 충분한 운동 기간 과 여러 기울임의 각도 변인들을 통해 질적인 연구와 초음파 디지털 영상 분석 또한 필요하다. 운동기간이 짧고 운동 강도도 적었지만 다 방향 동정 안정화 운동을 통해 나타난 변화는 긍정적으로 생각되며 향후 지속적인 연구가 필요하다고 생각된다.

\section{REFERENCES}

1. Muscolino JE, Cipriani S. Pilates and the "powerhouse" - I. Journal of BodyWork and Movement Therapies. 2004;8(1):15-24.

2. Arokoski JP, Valta T. Airaksinen O et al. Back and Abdominal muscle function during stabilization exercises. Arch Phys Med Rehabil. 2001; 82(8):1089-98.

3. Norris CM. Functional load abdominal training: part1. Phys Ther Sport. 2001;2(1):29-39.

4. Stevens VK, Coorevits PL, Bouche KG et al. The influence of specific training on trunk muscle recruitment patterns in healthy subjects during stabilization exercises. Man Ther. 2007;12(3):271-9.

5. Stevens VK, Bouche KG, Mahieu NN et al. Trunk muscle activity in healthy subjects during bridging stabilization exercises. BMC Musculoskelet Disord. 2006;20(7):75.

6. Hodges PW, Moseley GL. Pain and motor control of the lumbopelvic region: effect and possible mechanisms. J Electromyogr Kinesiol. 2003; 13(4):361-70.

7. Shim HB, Cho HY, Choi WH. Effects of the trunk stabilization exercise on muscle activity in lumbar region. J Kor phys Ther. 2014;26(1):33-40.

8. Lee WJ, Park S, Park JW. Influence of Trunk Stabilization Exercise upon the Lumbar Stabilization and Foot Pressure in Patients with Back Pain. J Kor phys Ther. 2014;2(1):21-6.

9. Kim CY, Kim HD. The Effect of Supplementary Shouting Technique on Muscle Activity to Rectus Abdominis and External Oblique During Crunch Exercise in Healthy Subjects. J Kor phys Ther. 2015;27(1):1-6.

10. Kim SH, Lee JI. Comparison of Trunk Muscle Activity during Static Standing Position and Standing Position on Therapeutic Climbing Wall. . J Kor phys Ther. 2014;2(1);27-32.

11. Markovic G, Sarabon N, Greblo Z et al. Effects of feedback-based balance and core resistance training vs. Pilates training on balance and muscle function in older women: A randomized-controlled trial. Arch Gerontol Geriatr. 2015;61(2):117-23.

12. Chen CH, Lin SF, Yu WH et al. Comparison of the test-retest reliability of the balance computerized adaptive test and a computerized posturography instrument in patients with stroke. Arch Phys Med Rehabil. 2014; 95(8):1477-83.

13. Karim H, Fuhrman SI, Sparto P et al. Functional brain imaging of multisensory vestibular processing during computerized dynamic posturog- 
raphy using near-infrared spectroscopy. NeuroImage. 2013;74(1):31825.

14. Cheng YY, Chen PY, Hsieh WL et al. Correlation of the composite equilibrium score of computerized dynamic posturography and clinical balance tests. J Clinic Geront Geri. 2012;3(2):77-81.

15. Kim SJ. The Changes of Co-contraction Patterns in Trunk and Lower Body Muscles with Multidirectional Tilting Motion on the Dynamic and Static Posturography. Daegu University Dissertation of Doctorate Degree. 2010.

16. Kim SH, Kim MJ. 3-Dimension Lumbar Stabilization Exercise has an Influence on Pain of Degenerative Disc Disease Patients and the Spinal Stabilization muscle strength. Journal Korean academy physical therapist. 2006;13(1):29-38.

17. Kwon WA, Yang KH, Lee JH. The Effects on 3-Dimensional Exercise of Lumber Stabilization for Chronic Low Back Pain. J Kor phys Ther. 2006; 18(5):25-34.

18. Shin SH, Yu M, Jeong GY et al. Effect on the Balance Ability after Four Week Training Using the System for 3-D Dynamic Exercise Equipment. 2012;6(2):1-8.

19. Hodges PW, Gandevia SC. Change in intre-abdominal pressure during postural and respiratory activation of the human diaphragm. J Appl Physiol. 2000;89(3):967-76.

20. Ging W. Correlations between transverses abdominis thickness, lumbar stability, and balance of female university students. J Phys Ther Sci. 2013; 25(6):681-3.

21. Calatayud J, Borreani S, Martin J et al. Core muscle activity in a series of balance exercises with different stability conditions. Gait Posture. 2015; 42(2):186-92.

22. Rankin G, Stokes M, Newham D. Size and shape of the posterior neck muscles measured by ultrasound imaging: normal values in males and females of different ages. Man Ther. 2005;10(2):108-15.

23. Lee JA, Kim SY. Reliability of Ultrasonography for The Lomgus Collo Asymptomatic Subjects. J Kor phys Ther. 2011;23(4):59-66.

24. McMeek JM, Beith ID, Newham DJ et al. The relationship between EMG and change in thickness of transverses abdominis. Clincal biomechanics. 2004;19(4):337-42.

25. Sahrmann SA. Diagnosis and treatment of movement impairment syndromes. Mosby. 2005:69-71.

26. Reeves NP, Cholewicki J, Milner T et al. Trunk antagonist co-activation is associated with impaired neuromuscular performance. Exp Brain Res. 2008;188(3):457-63.

27. Sugaya T, Abe Y, Sakamoto M. Ultrasound evaluation of muscle thickness changes in the external oblique internal oblique, and transversus abdominis muscle considering the influence of posture and muscle contraction. J Phys Ther Sci. 2014;26(9):1399-402.

28. Anders Ch, Gunther Brose. Activation characteristics of trunk muscle during whole body tilt with unsupported trunk. Institute for Pathophysiology and Pathobiochemistry, Motor Research Group. 2005.

29. Desmurget M, Grafton S. Forward modeling allows feedback control for fast reaching movements. Trend Cogn Sci. 2000;4(11):423-31.

30. Madhavan S, Shields RK. Movement accuracy changes muscle-activation strategies in female subjects during a novel single-leg weight-bearing task. PM R. 2009;1(4):319-28.

31. Sung PS Leininger PM. A kinematic and kinetic analysis of spinal region in subjects with and without recurrent low back pain during one leg standing. Clin Biomech. 2015;30(7):696-702.

32. Kang MH, Yoon JY, Yang JL et al. The Effect of visual biofeedback on EMG activity of trunk muscles and endurance holding time for correct position during whole-body tilt exercise. PTK. 2011;18(1):9-17. 